\title{
Nitrogênio e micronutrientes na produção de grãos de feijão-caupi inoculado ${ }^{1}$
}

\section{Nitrogen and micronutrients on grain yield of cowpea inoculated}

\author{
Raimundo Nonato Lopes Martins²; Rafaela Simão Abrahão Nóbrega ${ }^{3 *}$; \\ Alessandro Franco Torres Silva²; Júlio César Azevedo Nóbrega ${ }^{3}$; \\ Francisco Hélcio Canuto Amaral ${ }^{4}$; Elaine Martins Costa ${ }^{4}$; \\ José Ferreira Lustosa Filho5; Linnajara Vasconcelos Martins ${ }^{2}$
}

\section{Resumo}

O presente trabalho teve por objetivo avaliar o efeito da adubação nitrogenada e aplicação de micronutrientes na nodulação e produtividade do feijão-caupi inoculado com a cepa INPA 03 11B. $\mathrm{O}$ estudo foi conduzido na área experimental da Universidade Federal do Piauí, Bom Jesus, PI. O delineamento experimental utilizado foi em blocos casualizados, em esquema fatorial $5 \times 2$, com quatro repetições. Os tratamentos foram constituídos de cinco doses de nitrogênio $(0,35,70,105,140 \mathrm{~kg}$ $\left.\mathrm{ha}^{-1}\right)$, associadas ou não a aplicação foliar de micronutrientes (300 $\mathrm{g} \mathrm{ha}^{-1}$ de ácido bórico; $500 \mathrm{~g} \mathrm{ha}^{-}$ ${ }^{1}$ de sulfato de cobre, sulfato de manganês e sulfato de zinco e $60 \mathrm{~g} \mathrm{ha}^{-1}$ de molibdato de amônio). Avaliaram-se a nodulação, a massa seca da parte aérea, da raiz e total, eficiência relativa, componentes da produção, produtividade da cultura e acúmulo de $\mathrm{N}$ na parte aérea e nos grãos. As massas fresca e seca dos nódulos reduziram linearmente com aumento das doses de $\mathrm{N}$. Os componentes da produção não foram influenciados pelas doses de $\mathrm{N}$ e micronutrientes isoladamente e em conjunto. A aplicação de micronutrientes na ausência de $\mathrm{N}$ promoveu um incremento de $12,4 \%$ na produção de grãos de feijãocaupi inoculado.

Palavras-chave: Adubação, fixação biológica de $\mathrm{N}_{2}$, Vigna unguiculata

\begin{abstract}
This work aimed to study the effect of nitrogen and micronutrients addition on nodulation and on the productivity of cowpea inoculated with strain INPA 03 11B. The study was carried out in the experimental area of Universidade Federal do Piauí, Bom Jesus, PI. The experiment was a complete randomized block, with four replications and a $5 \times 2$ factorial arrangement. Treatments consisted of five nitrogen doses $\left(0,35,70,105,140 \mathrm{~kg} \mathrm{ha}^{1}\right)$, associated with and without foliar micronutrients application (300 $\mathrm{g} \mathrm{ha}^{1}$ boric acid; $500 \mathrm{~g} \mathrm{ha}^{1}$ copper sulphate, manganese sulphate, zinc sulphate and $60 \mathrm{~g}$ ha $^{1}$ ammonium molibdate). Nodulation, shoot, root and total dry mass, relative efficiency, components of
\end{abstract}

${ }^{1}$ Parte da Dissertação de mestrado do primeiro autor apresentada à Universidade Federal do Piauí, UFPI, Campus Professora Cinobelina Elvas, CPCE, Bom Jesus, PI.

2 Engenheiros Agrônomos, Discentes de Mestrado em Solos e Nutrição de Plantas, Campus Professora Cinobelina Elvas, CPCE, UFPI. Bom Jesus, PI. E-mail: provale@hotmail.com; alefrancotorres@hotmail.com; linnajaravasconcelos@hotmail.com

3 Profs. do Campus Professora Cinobelina Elvas, CPCE, UFPI, Bom Jesus, PI.E-mail: rafaela.nobrega@gmail.com; juliocnobrega@, gmail.com

4 Engenheiros Agrônomos, Discentes de Mestrado em Ciência do Solo, Universidade Federal de Lavras, UFLA, Lavras, MG. E-mail: helcioagro@gmail.com; elainemartins20@hotmail.com

${ }^{5}$ Discente de Enga Agra $^{\mathbf{a}}$, bolsista de iniciação científica do Campus Professora Cinobelina Elvas, CPCE, UFPI, Bom Jesus, PI. E-mail: ferreira@hotmail.com

* Autor para correspondência 
yield and crop productivity, besides $\mathrm{N}$ accumulation in shoot and grains were evaluated. Fresh and dry mass of nodules reduced linearly with the increase of $\mathrm{N}$ doses. Yield components were not affected by nitrogen and micronutrients fertilization. The application of micronutrients in the absence of nitrogen promoted an increase of $12.4 \%$ in grain yield of cowpea inoculated.

Key words: Fertilization, $\mathrm{N}_{2}$ biologic fixation, Vigna unguiculata

\section{Introdução}

O feijão-caupi [Vigna unguiculata (L.) Walp] é uma das culturas mais cultivadas no Estado do Piauí, principalmente por pequenos produtores, com baixo nível tecnológico, ocupando uma área de aproximadamente 210 mil hectares e produção de 51.675 Mg (FREIRE FILHO; LIMA; RIBEIRO, 2005). Apesar do destaque na produção, a produtividade média da cultura varia de 181 a 880 $\mathrm{kg} \mathrm{ha}^{-1}$, respectivamente, para as microrregiões da Chapada Extremo Sul Piauiense e Alto Parnaíba Piauiense (IBGE, 2006). As baixas produtividades verificadas no Estado podem ser atribuídas, dentre outros fatores, à baixa disponibilidade de nutrientes no solo, principalmente, o nitrogênio $(\mathrm{N})$ (GUALTER et al., 2008; XAVIER et al., 2008).

$\mathrm{O} N$ é um dos macronutrientes exigido em maior quantidade pelo feijão-caupi, que requer, para o seu desenvolvimento completo, uma quantidade superior a $100 \mathrm{~kg} \mathrm{ha}^{-1}$ (FREIRE FILHO; LIMA; RIBEIRO, 2005). A aplicação de fertilizantes nitrogenados constitui uma das principais formas de fornecimento de $\mathrm{N}$ às culturas. No entanto, o $\mathrm{N}$ mineral em solos tropicais pode apresentar baixa freqüência de respostas pelas culturas devido às grandes perdas por volatilização e lixiviação, além de onerar o custo de produção e causar impactos ambientais quando aplicado de forma inadequada (SORATTO et al., 2003; HUNGRIA et al., 2006; THORBURN et al., 2011).

Em virtude do alto custo dos fertilizantes nitrogenados e, também, das perdas do $\mathrm{N}$ no solo, contribuindo para a poluição ambiental, tornase necessário à busca de técnicas que possam maximizar sua eficiência de utilização (HUNGRIA et al., 2006; BONILLA; BOLAÑOS, 2009). Nesse contexto, o aproveitamento do $\mathrm{N}$ atmosférico por meio da fixação biológica de nitrogênio (FBN), realizada por bactérias diazotróficas em simbiose com várias espécies de leguminosas, a exemplo do feijão-caupi, pode ser uma alternativa importante na substituição total ou parcial dos adubos nitrogenados (HUNGRIA et al., 2006; SOARES et al., 2006; ELAKHAL et al., 2008).

A FBN é reconhecidamente eficiente em feijãocaupi, que quando bem nodulado, pode crescer independente de outras fontes de $\mathrm{N}$ e atingir altos níveis de produtividade (SOARES et al., 2006; ALMEIDA et al., 2010; COSTA et al., 2011). Entretanto, a nodulação e a FBN são influenciadas por diversos fatores edafoclimáticos, dentre os quais se destaca a disponibilidade de nutrientes (GUALTER et al., 2008; BONILLA; BOLAÑOS, 2009; SILVA et al., 2010).

$\mathrm{Na}$ literatura são vários os estudos que comprovam a inibição da FBN por doses elevadas de $\mathrm{N}$ aplicadas na forma mineral (NASCIMENTO et al., 2008; XAVIER et al., 2008; SILVA et al., 2009). Por outro lado, o uso de pequenas doses de $\mathrm{N}$ pode melhorar o crescimento das plantas e promover efeito sinergístico sobre a nodulação de algumas espécies de Leguminosas, tais como Vigna unguiculata (L.) Walp (XAVIER et al., 2008), Phaseolus vulgaris (MOURA et al., 2009) e Inga maginata (GONÇALVES; GOI; JACOB NETO, 1999).

Os micronutrientes, apesar de requeridos em doses baixas, são tão importantes quanto os macronutrientes para que as plantas possam se desenvolvere produzir satisfatoriamente (CERETTA et al., 2005; LANA et al., 2008; LEITE et al., 2009). Suas deficiências podem causar sérios problemas ao desenvolvimento das culturas como, queda de produtividade e, possivelmente, morte das plantas 
(MALAVOLTA; GOMES; ALCARDE, 2002). Alguns trabalhos demonstraram efeitos positivos da aplicação de micronutrientes sobre a nodulação e produtividade do feijão-caupi (GUALTER et al., 2007; LEITE et al., 2009).

O presente trabalho teve por objetivo avaliar o efeito da adubação nitrogenada e da aplicação de micronutrientes na nodulação e produtividade de feijão-caupi inoculado com a cepa INPA 0311B no Pólo de Produção Bom Jesus, PI.

\section{Material e Métodos}

O experimento foi conduzido em área experimental da Universidade Federal do Piaú, Bom Jesus, PI, (09 04' S, 44 21' W e altitude de $277 \mathrm{~m}$ ), no período de março a maio de 2010, em um Neossolo Quartzarênico, sem histórico de uso de inoculante.

O clima da região, segundo a classificação de Köppen, é do tipo Aw, tropical semi-árido quente, caracterizado por duas estações bem definidas, com um verão chuvoso e um inverno seco (CEPRO, 1992), com precipitação pluviométrica média de $1050 \mathrm{~mm} \mathrm{ano}^{-1}$. Os dados de precipitação, temperaturas máxima e mínima registradas no ano de 2010, encontram-se na Figura 1.

Figura 1. Temperaturas máxima, mínima e precipitação entre os meses de janeiro a junho de 2010, em Bom Jesus, PI.

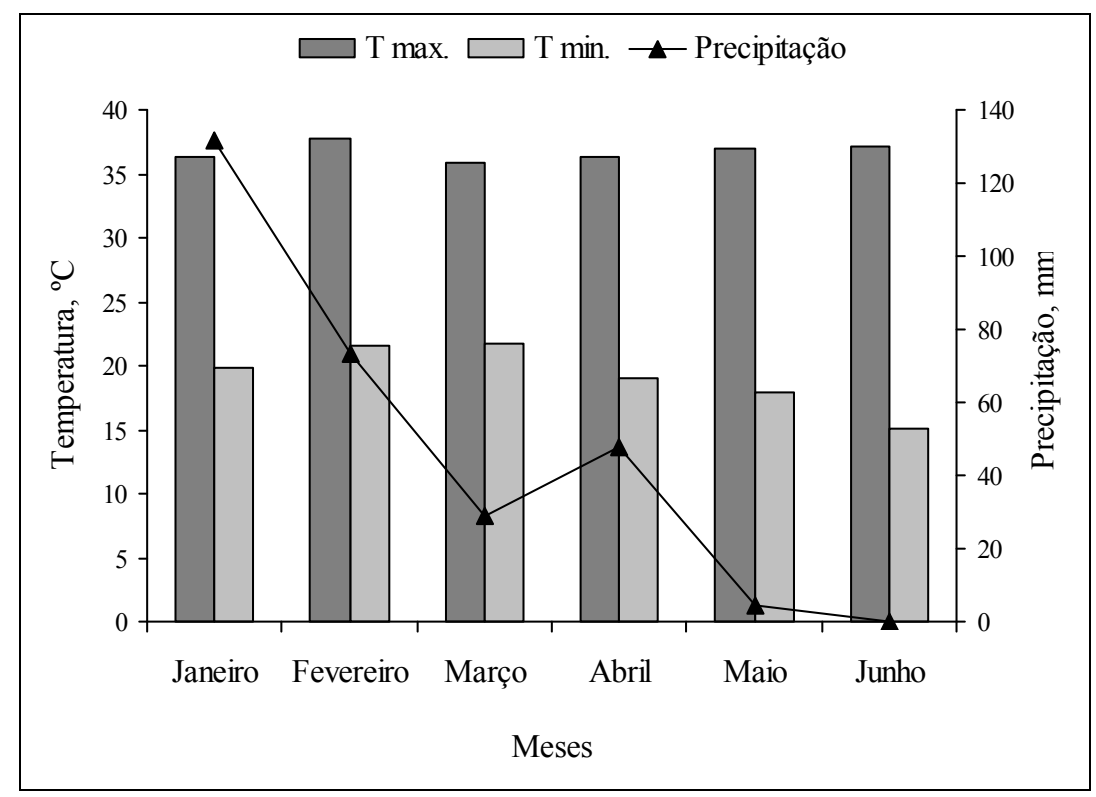

Fonte: Elaboração dos autores.

O experimento foi conduzido no período chuvoso e quando necessário foi aplicado uma lâmina média de irrigação de $30 \mathrm{~mm}$ a cada $48 \mathrm{~h}$, conforme dados de precipitação e temperatura mensais coletados na estação meteorológica próxima a área experimental (Figura 1).
As características químicas e físicas do solo avaliadas na camada de 0 a $0,2 \mathrm{~m}$ antes da instalação do experimento estão descritas na Tabela 1 .

O solo foi preparado com uma aração e duas gradagens. O delineamento experimental utilizado foi em blocos casualizados, em esquema fatorial 5 
x 2, com quatro repetições. Os tratamentos foram constituídos de cinco doses de $\mathrm{N}(0,35,70,105$, $140 \mathrm{~kg} \mathrm{ha}^{-1}$ ), associadas ou não a aplicação foliar de micronutrientes ( $300 \mathrm{~g} \mathrm{ha}^{-1}$ de ácido bórico; 500 $\mathrm{g} \mathrm{ha}^{-1}$ de sulfato de cobre, sulfato de manganês e sulfato de zinco e $60 \mathrm{~g} \mathrm{ha}^{-1}$ de molibdato de amônio).

Tabela 1. Características químicas e físicas do solo antes da implantação do experimento.

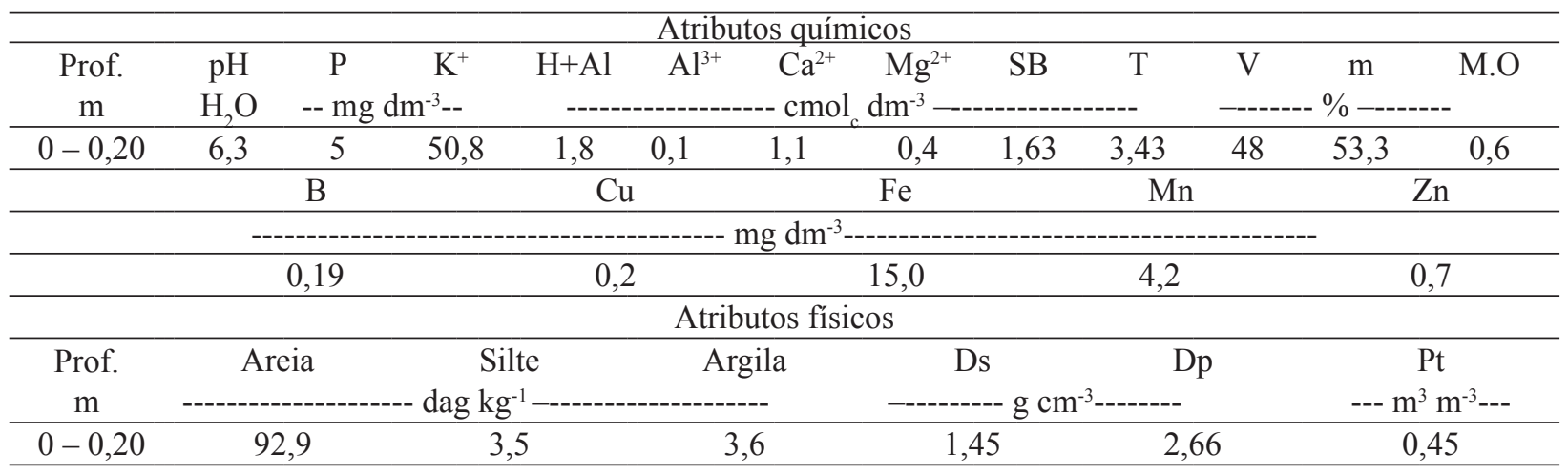

Fonte: Elaboração dos autores.

Para fornecimento de $\mathrm{N}$ utilizou-se como fonte uréia e as doses superiores a $35 \mathrm{~kg} \mathrm{ha}^{-1}$ foram parceladas em duas aplicações, sendo uma no plantio e outra 20 dias após a emergência das plantas (DAE). A aplicação dos micronutrientes foi realizada via foliar aos $25 \mathrm{DAE}$, de acordo com a recomendação para a cultura (GALRÃO, 2004), utilizando-se pulverizador manual. Para evitar a deriva e contaminação dos demais tratamentos foi utilizada uma barreira física durante a aplicação.

Todos os tratamentos receberam adubação fosfatada $\left(\mathrm{P}_{2} \mathrm{O}_{5}\right)$ e potássica $\left(\mathrm{K}_{2} \mathrm{O}\right)$ na dose de 60 e $40 \mathrm{~kg} \mathrm{ha}{ }^{-1}$ utilizando como fonte o superfosfato simples e cloreto de potássio, respectivamente, incorporados a seis $\mathrm{cm}$ de profundidade, conforme a recomendação para a cultura (FREIRE FILHO; LIMA; RIBEIRO, 2005).

Na semeadura foram utilizadas sementes de feijãocaupi, cultivar BR 17 Gurguéia, sendo inoculadas com a cepa INPA 0311B (Bradyrhizobium sp.), autorizada pelo Ministério da Agricultura Pecuária e Abastecimento (MAPA, 2010) e testada por Costa et al. (2011) para a região sul do Piauí. O inoculante foi preparado com turfa esterilizada em autoclave, na proporção 3:1 de turfa e cultura em meio 79 (FRED; WAKSMAN, 1928) semi-sólido na fase log (após cinco dias de crescimento com concentração mínima de $10^{8}$ células $\mathrm{g}^{-1}$ de inoculante).

As sementes foram inoculadas na proporção de $500 \mathrm{~g}$ do inoculante para $50 \mathrm{~kg}$ de sementes. A semeadura foi feita imediatamente após a inoculação, semeando-se três sementes por cova no espaçamento de $0,8 \times 0,20 \mathrm{~m}$. O desbaste foi efetuado aos $15 \mathrm{DAE}$, deixando duas plantas por cova. A parcela experimental correspondeu a $16 \mathrm{~m}^{2}$, com quatro fileiras de 5,0 m de comprimento, tendo como área útil as duas fileiras centrais. Durante o desenvolvimento da cultura foram realizadas capinas manuais.

No florescimento, aos 45 DAE, foram coletadas aleatoriamente, dez plantas de cada parcela para avaliação do número de nódulos por planta (NN), massa fresca de nódulos (MFN), massa seca de nódulos (MSN), produção de massa seca da parte aérea (MSPA), da raiz (MSR) e total (MST) e eficiência relativa (EFR). Depois da pesagem, a parte aérea foi moída para a determinação do teor e acúmulo de N (ANPA). 
A segunda avaliação foi realizada na colheita, quando foram escolhidas dez plantas da área útil de cada parcela. Posteriormente, todas as vagens foram secas ao ar e trilhadas para avaliação do número de vagens por planta (NVPL), peso de vagens por planta (PVPL), número de sementes por vagem (NSV); comprimento de vagem por planta (CVP) e rendimento de grãos por hectare (REND). Depois da pesagem, os grãos foram moídos para a determinação do teor e acúmulo de $\mathrm{N}$ nos grãos (ANG).

Para a determinação da produção de massa seca, a parte aérea foi acondicionada em sacos de papel e depositada em estufa com ventilação forçado à 65 ${ }^{\circ} \mathrm{C}$ até atingir peso constante. A eficiência relativa da cepa foi calculada pela fórmula: $\mathrm{EFR}=(\mathrm{MSPA}$ inoculada)*100/(MSPA da planta adubada com $\mathrm{N}$ mineral). O ANPA e ANG foram calculados multiplicando-se o peso da massa seca da parte aérea $(\mathrm{g})$ ou dos grãos $(\mathrm{kg})$ pelo respectivo teor de $\mathrm{N}$ e dividido por cem. $\mathrm{O}$ teor de $\mathrm{N}$ na parte aérea e nos grãos foi determinado pelo método semimicro
Kjeldahl (LIAO, 1981). Para avaliar o rendimento de grãos, a sua umidade foi corrigida para $13 \%$.

Os resultados obtidos foram submetidos à análise de variância e comparações múltiplas de médias pelo teste de Tukey e análise de regressão polinomial a $5 \%$ de probabilidade, com auxílio do programa estatístico SISVAR (FERREIRA, 2000). Para a variável número de nódulos os dados foram transformados pela raiz quadrada de $\mathrm{Y}+0,5$.

\section{Resultados e Discussão}

$\mathrm{Na}$ primeira avaliação, realizada por ocasião do florescimento, foi verificado efeito significativo das doses de N sobre as variáveis MFN, MSN, MSPA, MSR, MST, EFR e ANPA.

Para as variáveis MFN e MSN foram verificadas respostas lineares decrescentes em função do aumento da adubação nitrogenada, evidenciando, assim, o papel inibidor do N-mineral sobre a nodulação de feijão-caupi (Figura 2 a e b).

Figura 2. a) Massa fresca (MFN) e seca b) (MSN) de nódulos de feijão-caupi inoculado com a cepa INPA 03 11B, em um Neossolo Quartzarênico da região de Bom Jesus, PI, submetido a doses de N, e avaliado aos 45 dias após a emergência.

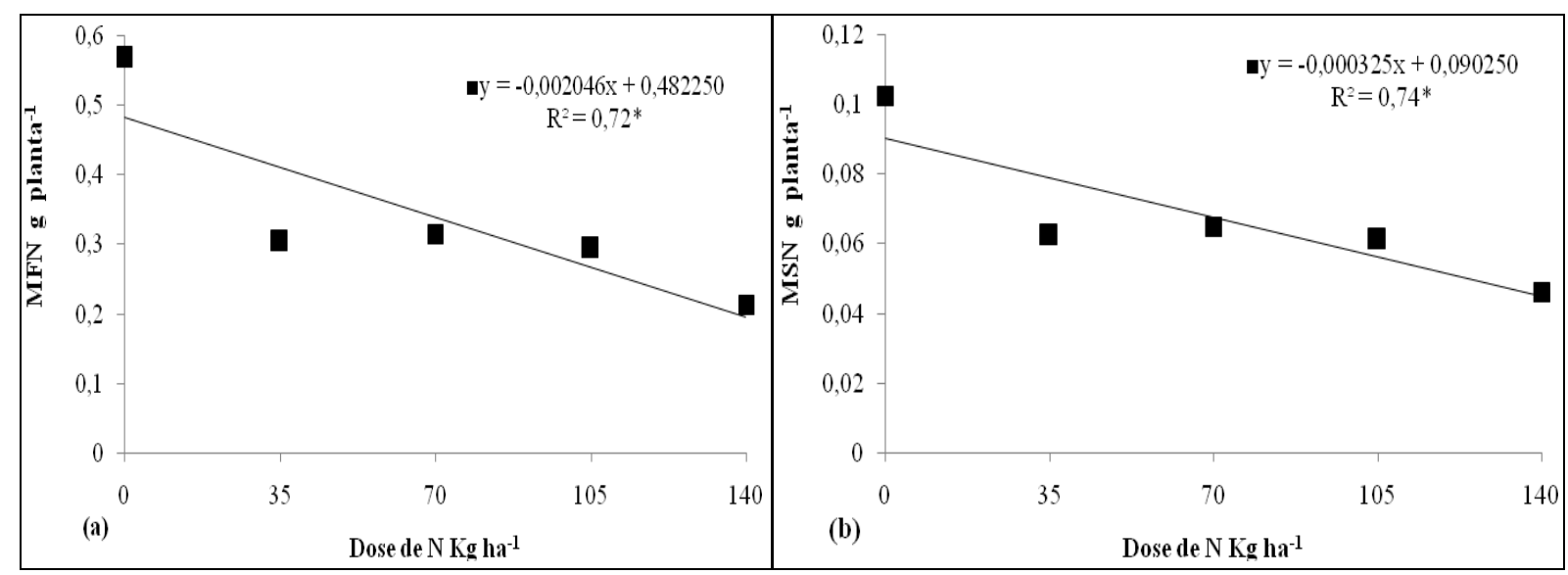

Fonte: Elaboração dos autores. 
Resultados semelhantes a este foram obtidos por Silva et al. (2009), ao avaliarem a inoculação do Phaseolus vulgaris com a cepa de Rhizobium tropici associada a diferentes doses de N. Os referidos autores verificaram que a adubação nitrogenada reduziu linearmente a massa seca de nódulos à medida que houve aumento nas doses $(0,40,80 \mathrm{e}$ $120 \mathrm{~kg} \mathrm{ha}^{-1} \mathrm{de} \mathrm{N}$ ). Este fato também foi observado por Pelegrin et al. (2009) ao avaliarem a resposta do Phaseolus vulgaris à inoculação com rizóbio e parcelamento de fertilizante nitrogenado.

Vários estudos comprovam a inibição da FBN por doses elevadas de $\mathrm{N}$ aplicadas na forma mineral (NASCIMENTO et al., 2008; XAVIER et al., 2008; SILVA et al., 2009). Ao estudar a influência da inoculação e adubação nitrogenada nas doses de 0 ,
$20,40,80$ e $160 \mathrm{~kg} \mathrm{ha}^{-1}$ de $\mathrm{N}$ sobre a nodulação e a produtividade de feijão-caupi em um Neossolo Quartzarênico no município de Parnaíba, PI, Xavier et al. (2008), verificaram redução significativa da MSN sob doses superiores a $80 \mathrm{~kg} \mathrm{ha}^{-1}$ de $\mathrm{N}$. Nascimento et al. (2008) ao estudarem o efeito da adubação nitrogenada e da cobertura vegetal no processo de inoculação em feijão-caupi em um Cambissolo Húmico no município de Crato, CE, observaram que as menores produções de MSN foram obtidas em plantas fertilizadas com $\mathrm{N}$ mineral $\left(50 \mathrm{~kg} \mathrm{ha}^{-1}\right)$.

Quanto à produção de MSR (Figura $3 \mathrm{a}$ ), a dose máxima estimada foi de 99,56 $\mathrm{kg}$ de $\mathrm{N} \mathrm{ha}^{-1}$ que possibilitou uma produção de $17,57 \mathrm{~g} \mathrm{planta}^{-1}$. Para a MSPA (Figura 3 b), o valor máximo estimado foi de $117,39 \mathrm{~g} \mathrm{planta}^{-1}$ para a dose de $89,29 \mathrm{~kg} \mathrm{ha}^{-1}$.

Figura 3. a) Massa seca de raiz (MSR), b) parte aérea (MSPA), c) total (MST) e d) eficiência relativa (EFR) de feijãocaupi inoculado com a cepa INPA 03 11B, em um Neossolo Quartzarênico da região de Bom Jesus, PI, submetido a doses de N, e avaliado aos 45 dias após a emergência.

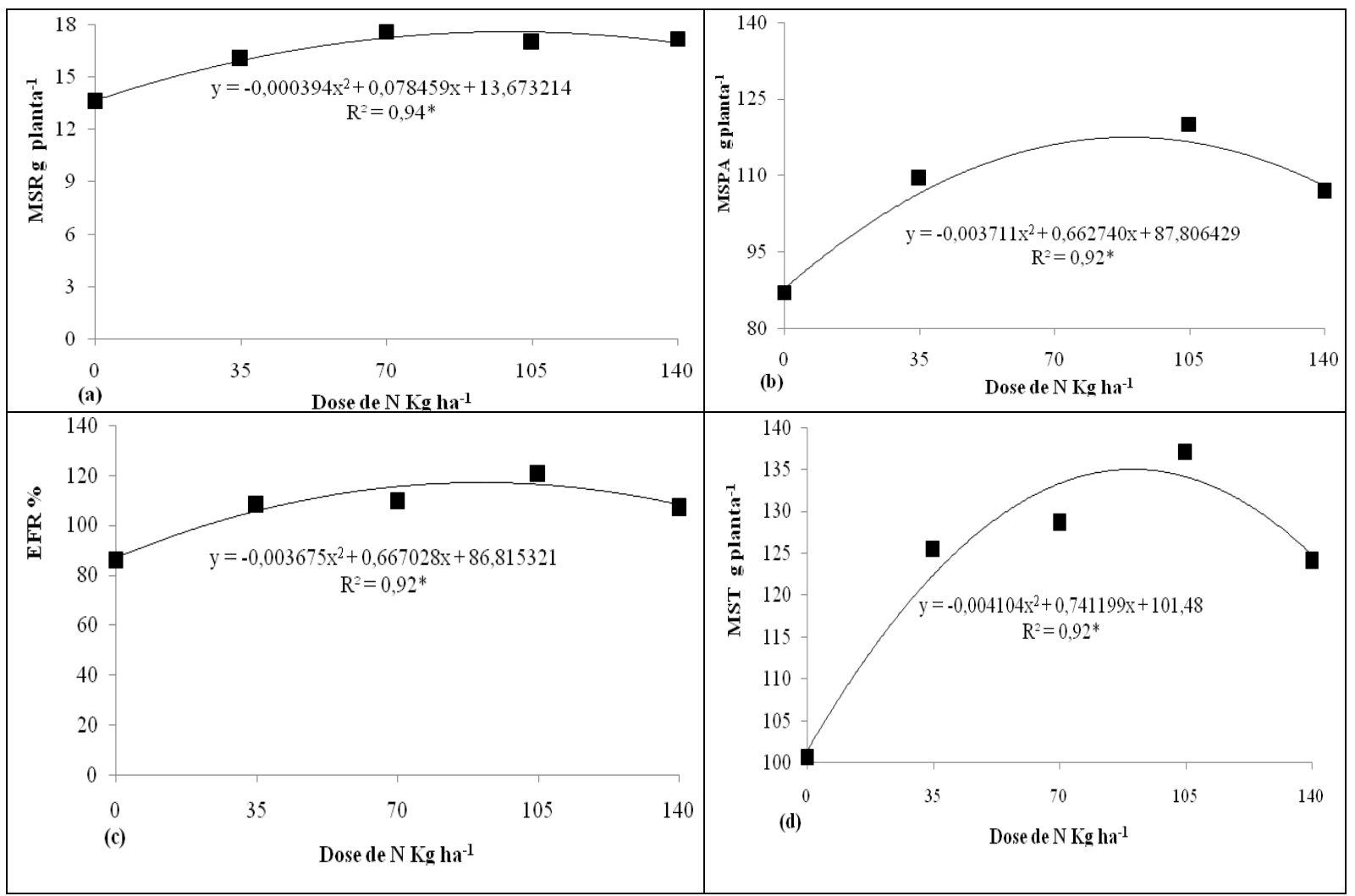

Fonte: Elaboração dos autores. 
Neste resultado, além dos efeitos negativos na produção de biomassa vegetal, a aplicação de doses excessivas de $\mathrm{N}$, pode aumentar o custo de produção e danos ambientais, por apresentar elevado custo energético na sua produção, promover a contaminação das águas superficiais e subterrâneas, em virtude de perdas por erosão e lixiviação (THORBURN et al., 2011).

Para MST e EFR (Figuras $3 \mathrm{c}$ e d) as doses estimadas de $\mathrm{N}$ foi $90,3 \mathrm{~kg} \mathrm{ha}^{-1}$ com produção de 134,9 g de MST planta-1 e $90,8 \mathrm{~kg} \mathrm{ha}^{-1}$ para a maior
EFR (117,0 \%), indicando que a eficiência da cepa inoculante utilizada neste ensaio é reduzida na presença de doses elevadas de $\mathrm{N}$, acima da máxima estimada $\left(90,7 \mathrm{~kg}\right.$ de $\left.\mathrm{N} \mathrm{ha}^{-1}\right)$.

Com relação ao ANPA (Figura 4) foi verificado comportamento semelhante ao da MSPA e MST, sendo que a dose máxima estimada foi $98,9 \mathrm{~kg} \mathrm{ha}^{-1}$ para um acúmulo de 308,7 $\mathrm{mg}$ planta $^{-1}$, evidenciando uma redução do acúmulo de $\mathrm{N}$ no feijão-caupi em função do aumento das doses de $\mathrm{N}$ estudadas superiores a máxima estimada.

Figura 4. Acúmulo de nitrogênio na parte aérea (ANPA) de feijão-caupi inoculado com a cepa INPA $0311 \mathrm{~B}$, em um Neossolo Quartzarênico da região de Bom Jesus, PI, submetido a doses de N e avaliado aos 45 dias após a emergência.

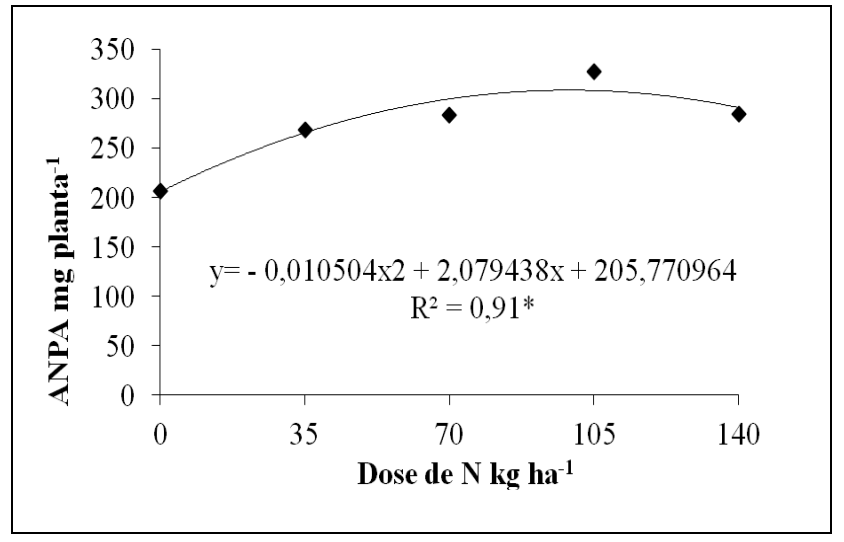

Fonte: Elaboração dos autores.

Na segunda avaliação, por ocasião da colheita, apenas a variável REND foi influenciada significativamente, havendo efeito dos fatores doses de $\mathrm{N}$ e micronutrientes isoladamente e em conjunto (interação doses de $\mathrm{N}$ e micronutrientes).

A ausência de efeito dos fatores estudados sobre as variáveis NVPL, PVPL, NSV, CVP, que representam importantes componentes de produção para a cultura, consideradas junto com rendimento de grãos, prioritárias em programa de melhoramento genético (OLIVEIRA et al., 2002), comprova a eficiência da cepa inoculante utilizada (INPA 0311B) em suprir a necessidade de $\mathrm{N}$ da cultura no Pólo de Produção de Bom Jesus, concordando com Costa et al. (2011). Já Xavier et al. (2008), avaliando o efeito da adubação nitrogenada e inoculação com a cepa BR2001 (Bradyrhizobium sp.) em feijãocaupi, verificaram que pequena quantidade de $\mathrm{N}$ (20 $\mathrm{kg} \mathrm{ha}^{-1}$ ) juntamente com a inoculação aumentaram significativamente a produção de grãos no município de Parnaíba, PI.

Analisando a interação entre doses de N e micronutrientes, observou-se que o maior rendimento de grãos $\left(784,0 \mathrm{~kg} \mathrm{ha}^{-1}\right)$ foi obtido na ausência de $\mathrm{N}$ (dose de $0 \mathrm{~kg} \mathrm{ha}^{-1} \mathrm{~N}$ ) com adição de micronutrientes em relação ao sem adição de micronutrientes $\left(687,0 \mathrm{~kg} \mathrm{ha}^{-1}\right)$, resultando em um incremento de 12,4\% (Figura 5).

As maiores doses de $\mathrm{N}$ podem ter influenciado negativamente a produção de grãos pelo estímulo 
ao desenvolvimento vegetativo da cultura, em detrimento da produção de grãos. O efeito positivo da aplicação de micronutrientes sobre a produção de grãos verificados neste trabalho corrobora os resultados obtidos por diversos autores em trabalhos realizados com leguminosas (CERETTA et al., 2005; LANA et al., 2008; LEITE et al., 2009). Resultados positivos da adição individualizada de Mo foram relatados por Leite et al. (2009) na dose de $60 \mathrm{~g} \mathrm{ha}^{-1}$ em conjunto com inoculação para feijão-caupi.

Figura 5. Rendimento de grãos de feijão-caupi inoculado com a cepa INPA 03 11B, em um Neossolo Quartzarênico da região de Bom Jesus, PI, submetido a doses de N.

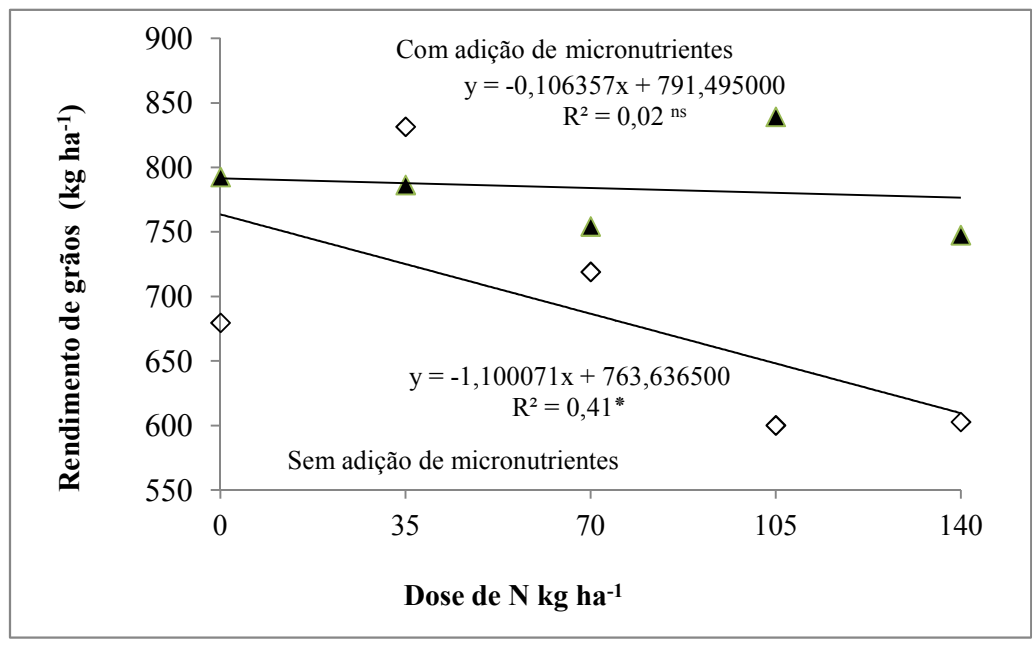

Fonte: Elaboração dos autores.

Considerando que a produtividade média nas diferentes microrregiões do estado do Piaú em cultivo de primeira safra fica em torno de 369 $\mathrm{kg} \mathrm{ha}^{-1}$ (IBGE, 2006), a inoculação associada à fertilização com micronutrientes (Mo, B, $\mathrm{Zn}, \mathrm{Cu}$ e $\mathrm{Mn}$ ) promoveu um acréscimo superior a $100 \%$ na produtividade. Ao contrário do verificado no presente estudo, Gualter et al. (2008), trabalhando com a cepa BR 3262 (Bradyrhizobium elkanii), adubação fosfatada, potássica e molibídica em Neossolo Flúvico eutrófico não observaram incremento na produtividade da cultura de feijãocaupi, cultivar BRS Guariba. Essa divergência de respostas pode estar relacionada às diferenças quanto à disponibilidade de nutrientes presentes nos solos, e também a eficiência simbiótica das cepas inoculante utilizados no cultivo do feijão-caupi.

Os problemas ambientais e elevados preços dos adubos nitrogenados tem mostrado que a FBN é indispensável para garantia da sustentabilidade dos agroecossistemas, pois, além de apresentar baixo custo econômico traz diversos benefícios como, o aumento da produção vegetal, recuperação de áreas degradadas, incremento da fertilidade e matéria orgânica do solo (MAESTRE et al., 2006; NASCIMENTO et al., 2008; FRANCHE; LINDSTROM; ELMERICH, 2009). No presente estudo esse processo comprovadamente apresentouse como uma alternativa viável para a substituição total da adubação nitrogenada na cultura do feijãocaupi no Pólo de Produção de Bom Jesus, PI, para pequenos e grandes produtores.

\section{Conclusões}

A maior produção de massa fresca e seca de nódulos foi obtida na ausência da adubação nitrogenada, não havendo efeito da aplicação de micronutrientes na nodulação de feijão-caupi inoculado com a cepa INPA $0311 \mathrm{~B}$. 
O maior rendimento de grãos de feijão-caupi inoculado com a cepa INPA $0311 \mathrm{~B}$ foi obtido na ausência de adubação nitrogenada com aplicação de micronutrientes, resultando em incremento de $12,4 \%$ em relação à ausência da aplicação.

As doses de nitrogênio e aplicação de micronutrientes não influenciaram os componentes da produção do feijão-caupi inoculado com a cepa INPA $0311 \mathrm{~B}$.

\section{Agradecimentos}

Os autores agradecem ao Conselho Nacional de Desenvolvimento Científico e Tecnológico (CNPq), Ministério da Agricultura Pecuária e Abastecimento (MAPA) e Secretaria de Desenvolvimento da Agricultura/SDA pela auxilio financeiro ao projeto. Ao Programa Nacional de Cooperação Acadêmica (PROCAD) que possibilitou o intercâmbio com a Universidade Federal de Lavras (UFLA), Departamento de Ciência do Solo (DCS).

\section{Referências}

ALMEIDA, A. L. G.; ALCÂNTARA, R. M. C. M.; NÓBREGA, R. S. A.; LEITE, L. F. C.; SILVA, J. A. L.; NÓBREGA, J. C. A. Produtividade do feijão-caupi cv BR 17 Gurguéia inoculado com bactérias diazotróficas simbióticas no Piauí. Revista Brasileira de Ciências Agrárias, Recife, v. 5, n. 3, p. 364-369, 2010.

BONILLA, I.; BOLAÑOS, L. Mineral nutrition for legume-rhizobia symbiosis: B, Ca, N, P, S, K, Fe, Mo, $\mathrm{Co}$, and Ni: a review. Organic Farming, Pest Control and Remediation of Soil Pollutants, Lighthouse, v. 1, p. 253274, 2009.

CEPRO. Perfil dos municípios piauienses. Teresina, PI: Fundação Cepro, 1992. 420 p.

CERETTA, C. A.; PAVINATO, A.; PAVINATO, P. S.; MOREIRA, I. C. L.; GIROTTO, E.; TRENTIN, E. Micronutrientes na soja: produtividade e análise econômica. Revista Ciência Rural, Santa Maria, v. 35, n. 3, p. 576-581, 2005.

COSTA, E. M.; NÓBREGA, R. S. A.; MARTINS, L. V.; AMARAL, F. H. C.; MOREIRA, F. M. S. Nodulação e produtividade de Vigna unguiculata (L.) Walp. por cepas de rizóbio em Bom Jesus, PI. Revista Ciência Agronômica, Fortaleza, v. 42, n. 1, p. 1-7, 2011.

EL-AKHAL, M. R.; RINCON, A.; ARENAL, F.; LUCAS, M. M.; EL MOURABIT, N.; BARRIJAL, S.; PUEYO, J. J. Genetic diversity and symbiotic efficiency of rhizobial isolates obtained from nodules of Arachis hypogaea in Northwestern Morocco. Soil Biology \& Biochemistry, Elmsford, v. 40, n. 11, p. 2911-2914, 2008.

FERREIRA, D. F. Análises estatísticas por meio do Sisvar para Windows 4.0. In: REUNIÃO ANUAL BRASILEIRA DA SOCIEDADE INTERNACIONAL DE BIOMETRIA, 45., 2000, São Carlos. Anais... São Carlos: UFSC, 2000. p. 255-258.

FRANCHE, C.; LINDSTROM, K.; ELMERICH, C. Nitrogen-fixing bacteria associated with leguminous and non-leguminous plants. Plant and Soil, The Hague, v. 321, p. 35-59, 2009.

FRED, E. B.; WAKSMAN, S. A. Laboratory manual of general microbiology. New York: McGraw-Hill Book Company, 1928. 143 p.

FREIRE FILHO, F. R.; LIMA, J. A. A.; RIBEIRO, V. Q. Feijão-caupi: avanços tecnológicos. Brasília, DF: Embrapa Informações Tecnológicas, 2005. 519 p.

GALRÃO, E. Z. Micronutrientes. In: SOUSA, D. M. G.; LOBATO, E. Cerrado: correção do solo e adubação. Planaltina: Brasília: Embrapa, 2004. p. 185-226.

GONÇALVES, C. A.; GOI, S. R.; JACOB NETO, J. Crescimento e nodulação de Inga marginata em resposta à adição de nitrogênio, fósforo e inoculação com rizóbio. Revista Floresta e Ambiente, Seropédica, v. 6, n. 1, p. 118-126, 1999.

GUALTER, R. M. R.; LEITE, L. F. C.; ALCANTARA, R. M. C. M.; COSTA, D. B.; LIMA, S. S. Avaliação dos efeitos da inoculação de feijão-caupi [Vigna unguiculata (L.) Walp.] com Bradyrhizobium elkanii. Revista Brasileira de Agroecologia, Cruz Alta, v. 2, n. 2, p. 637640, 2007.

GUALTER, R. M. R.; LEITE, L. F. C.; ARAUJO, A. S. F.; ALCANTARA, R. M. C. M.; COSTA, D. B. Inoculação e adubação mineral em feijão-caupi: Efeitos na nodulação, crescimento e produtividade. Scientia Agraria, Curitiba, v. 9, n. 4, p. 469-474, 2008.

HUNGRIA, M.; FRANCHINI, J. C.; CAMPO, R. J.; CRISPINO, C. C.; MORAES, J. Z.; SIBALDELLI R, N. R.; MENDES, I. C.; ARIHARA, J. Nitrogen nutrition of soybean in Brazil: contributions of biological $\mathrm{N}_{2}$ fixation and $\mathrm{N}$ fertilizer to grain yield. Canadian Journal of Plant Science, Ottawa, v. 86, p. 927-939, 2006. 
INSTITUTO BRASILEIRO DE GEOGRAFIA E ESTATÍSTICA - IBGE. Culturas temporárias da região nordeste. Disponível em: <http://www.ibge.gov.br/ home/estatistica/indicadores/agropecuaria/Ispa/defalt. shtm>. Acesso em: 20 dez. 2006.

LANA, R. M. Q.; PEREIRA, R. P.; LANA, A. M. Q.; FARIA, M. V. Utilização de micronutrientes na cultura do feijoeiro cultivado no sistema plantio direto. Bioscience Journal, Uberlândia, v. 24, n. 4, p. 58-63, 2008.

LEITE, L. F. C.; ARAÚJO, A. S. F.; COSTA, C. N.; RIBEIROS, A. M. B. Nodulação e produtividade de grãos do feijão-caupi em resposta ao molibdênio. Revista Ciência Agronômica, Fortaleza, v. 40, n. 4, p. 492-497, 2009.

LIAO, C. F. H. Devarda's alloy methods for total nitrogen determination. Soil Science Society of America Journal, Madison, v. 45, n. 5, p.852-855, 1981.

MAESTRE, F. T.; MARTIN, N.; DIEZ, B.; LOPEZPOMA, R.; SANTOS, F.; LUQUE, I.; CORTINA, J. Watering, fertilization, and slurry inoculation promote recovery of biological crust function in degraded soils. Microbial Ecology, New York, v. 52, n. 3, p. 365-377, 2006.

MALAVOLTA, E.; GOMES, F. P.; ALCARDE, J. C. Adubos e adubações. 2. ed. São Paulo: Nobel, 2002. 200 p.

MINISTÉRIO DA AGRICULTURA, PECUÁRIA E ABASTECIMENTO - MAPA. Decreto n.7.127, 4 de março de 2010. 2010. Disponível em: <http://anfip. datalegis.inf.br/view/txato.php?key $=\&$ word $=\&$ tipo $=$ inm \&numero $=00000013 \&$ seq $=000 \&$ ano $=2011 \&$ orgao $=$ sda $/$ mapa\&tipitem $=\&$ desitem $=>$. Acesso em: 20 jun. 2010.

MOURA, J. B.; GUARESCHI, R. F.; CORREIA, A. R.; GAZOLLA, P. R.; CABRAL, J. S. R. Produtividade do feijoeiro submetido à adubação nitrogenada e inoculação com Rhizobium tropici. Global Science and Technology, Rio Verde, v. 2, n. 3, p. 66-71, 2009.

NASCIMENTO, C. S.; LIRA JÚNIOR, M. A.; STAMFORD, N. P.; FREIRE, M. B. G. S.; SOUSA, C. A. Nodulação e produção do caupi (Vigna unguiculata L. Walp) sob efeito de plantas de cobertura e inoculação. Revista Brasileira de Ciência do Solo, Viçosa, v. 2, n. 2, p. 579-587, 2008.
OLIVEIRA, A. P.; SOBRINHO, J. T.; NASCIMENTO, J. T.; ALVES, A. U.; AUBURQUEQUE, I. C.; BRUNO, G. B. Avaliação de linhagens e cultivares de feijão-caupi em Areia, PB. Horticultura Brasileira, Brasília, v. 20, n. 2, p. 180-182, 2002.

PELEGRIN, R.; MERCANTE, F. M.; OTSUBO, I. M.; OTSUBO, A. A. Resposta da cultura do feijoeiro à adubação nitrogenada e à inoculação com rizóbio. Revista Brasileira de Ciência do Solo, Viçosa, v. 33, n. 1, p. 219-226, 2009.

SILVA, E. F. L.; ARAÚJO, A. S. F.; SANTOS, V. B.; NUNES, L. A. P. L.; CARNEIRO, R. F. V. Fixação biológica do $\mathrm{N}_{2}$ em feijão-caupi sob diferentes doses e fontes de fósforo solúvel. Bioscience Journal, Uberlândia, v. 26, n. 3, p. 394-402, 2010.

SILVA, E. F.; MARCHETTI, M. E.; SOUZA, L. C. F.; MERCANTE, F. M.; RODRIGUES, E. T.; VITORINO, A. C. T. Inoculação do feijoeiro com Rhizobium tropici associada à exsudato de Mimosa flocculosa com diferentes doses de nitrogênio. Bragantia, Campinas, v. 68, n. 2, p. 443-451, 2009.

SOARES, A. L. L.; PEREIRA, J. P. A. R.; FERREIRA, P. A. A.; VALE, H. M. M.; LIMA, A. S.; ANDRADE, M. J. B.; MOREIRA, F. M. S. Eficiência agronômica de rizóbios selecionados e diversidade de populações nativas nodulíferas em Perdões (MG). I - caupi. Revista Brasileira de Ciência do Solo, Viçosa, v. 30, p. 795-802, 2006.

SORATTO, R. P.; ARF, O.; RODRIGUES, R. A. F.; BUZETTI, S.; SILVA, T. R. B. Resposta do feijoeiro ao preparo do solo, manejo de água e parcelamento do nitrogênio. Acta Scientiarum: Agronomy, Maringá, v. 25, n. 1, p. 89-96, 2003.

THORBURN, P. J.; BIGGS, J. S.; WEBSTER, A. J.; BIGGS, I. M. An improved way to determine nitrogen fertiliser requirements of sugarcane crops to meet global environmental challenges. Plant and Soil, The Hague, v. 339, n. 1-2, p. 51-67, 2011.

XAVIER, T. F.; ARAÚJO, A. S. F.; SANTOS, V. B.; CAMPOS, F. L. Inoculação e adubação nitrogenada sobre a nodulação e a produtividade de grãos de feijãocaupi. Revista Ciência Rural, Santa Maria, v. 38, n. 7, p. 2037-2041, 2008. 